\title{
HIV-prevention studies: Educate smarter, boost women's earning power
}

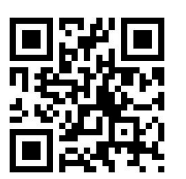

Two pilot studies that have been teaching incomebuilding, communication and relationship skills to men and women in 3 informal settlements around Durban have nearly tripled participants' earnings, and dramatically reduced intimate partner violence (IPV). The test probes could form the basis of an ambitious bid to address poverty and IPV, both major structural drivers of the HIV pandemic in South Africa, where gender relations are 'incredibly patriarchal', said lead researcher Professor Rachel Jewkes, Director of the Medical Research Council (MRC's) Gender and Health Research Unit.

The interventions are known as 'Creating Futures' and 'Stepping Stones', and are jointly conducted by the University of KwaZuluNatal's Health Economics and HIV/AIDS Research Division (HEARD), the MRC and the non-profit organisation (NGO), Project Empower. They show huge potential for scale-up without micro-financing or financial hand-outs. In the pilot studies, 233 people of both sexes (averaging 21 years old) participated in both interventions over 3 months. The result was that men became less controlling and developed more equitable attitudes. Men also experienced less depression, fewer suicidal thoughts and higher perceived life satisfaction, while both genders had higher incomes, more shock resilience and less stress about work.

In Durban on 19 June, Jewkes told a session on Behavioural Change Communication at the 6th South African AIDS conference that the studies show promise as a way of helping the 'very hard-to-reach' youth of informal settlements countrywide. 'Although it was done in a small community, we need to think of feasible ways in which we can scale up similar interventions,' she added.

The original study began with the Stepping Stones project, which consists of 10 3-hour sessions covering listening and communication, 'how we act and what shapes it', sex and love, contraception and conception, taking risks and unwanted pregnancy, STDs and HIV, safer sex and condoms, gender-based violence, motivations for sexual behaviour and communication skills. Two years after the start of the study, Herpes Simplex Virus 2 (HSV-2) infections were reduced by a third

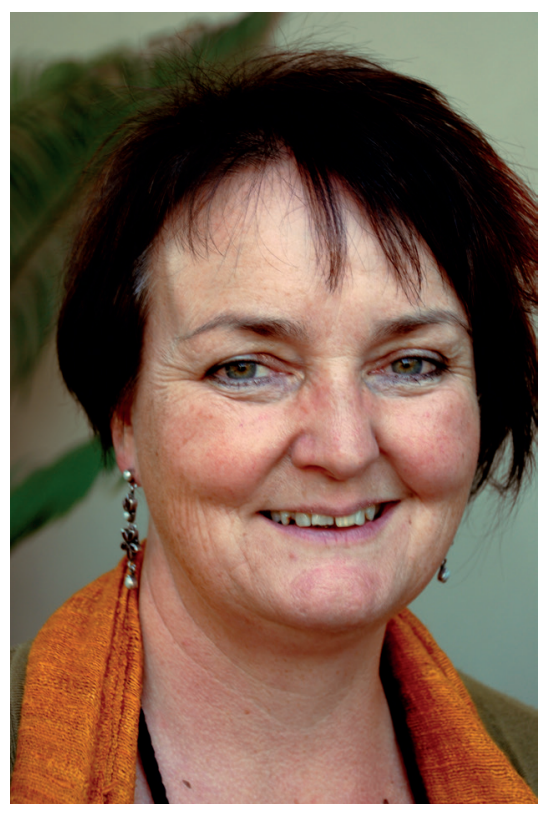

Professor Rachel Jewkes, Director of the Medical Research Council's Gender and Health Research Unit.

in men and women and men's perpetration of IPV was reduced by $38 \%$. However, Stepping Stones alone did not reduce women's exposure to violence.

The researchers hypothesised that women need to be economically empowered to effectively protect themselves against men's violence. Thus Creating Futures was born: 11 sessions encouraging participants to reflect on and critically analyse their livelihoods and develop skills for strengthening them, using existing resources. Sessions covered additional resources needed, social resources, education and learning, getting and keeping jobs, income generating opportunities, saving and coping with shocks.

\section{Finding: It pays to be male}

One eloquent socio-economic indicator that emerged was how the monthly incomes of men v. women compared - and increased - over the period of the Creating Futures study. Men on average earned R359/month initially, rising to R1015/month. Women initially earned R140/month, rising to R484/month. Over 4 times as many women as men were receiving social grants at the outset of the study, rising to nearly 5 times at study completion, while male grants dropped off by just over $1 \%$. Theft in the past month, due to lack of money, dropped by an average of $10 \%$ for both genders.

\section{Condoms in the bush}

The behaviour-change session also included an overview of a unique condom distribution project that increased condom take-up by $237 \%$ in poorly served rural and semi-rural communities in KwaZulu-Natal's Cedara, Hilton and Howick West districts. Dubbed the 'S'Khoko Bushcan Initiative' (S'Khoko means 'wise, responsible male leader' in Zulu), the project nailed steel containers called 'condocans' to trees along heavilyused rural bush pathways. The cans were restocked whenever necessary. Over a 10-week period ending in December last year, the researchers and their fieldworkers distributed 20025 condoms, with annual distribution climbing to 63925 .

The project is the brainchild of Jacqueline Pienaar, Male Medical Circumcision Lead in South Africa for the US Centre for Disease Control, and a fellow of its NGO, the MAC AIDS Fund. S'Khoko was conceived as a solution to the long distances and travel costs facing rural people who want to visit clinics and hospitals where free condom supplies are usually centralised. It is also primarily women who visit clinics, and men are notorious for avoiding healthcare facilities. Pienaar added that the project also eliminated any embarrassment or shame for individuals stocking up on condoms.

Pienaar said the initial uptake of male condoms in her pilot project (which has since been sustained and expanded) was 'huge', but explained that this was an 'initial grab' motivated by fear that supplies would run out. Once users were confident that the condocans would be restocked twice a week, uptake levelled off. Mixing brands and colours of condom packaging increased uptake and not a single condocan was lost, stolen or damaged. Residents surveyed were 'grateful and pleased', recommending other nearby areas for implementation.

However, Pienaar noted that female condoms proved unpopular, except for use as a partially effective sanitary 'pad' or for extraction of the large and smaller rings for decorative use as (dyed) bangles. Fieldworkers found femidoms strewn about below the condocans, perhaps indicating the community's 
disdain for them. During a question and answer session, Pienaar suggested that as Love Life is about to distribute 600000 female condoms throughout the country, widespread education on their benefits beforehand could significantly increase uptake and alter attitudes and social norms. She emphasised that femidoms remain a 'key empowering intervention' and worth pursuing.

\section{Men a headache for health minister}

In his opening address to the conference, National Health Minister Dr Aaron Motsoaledi alluded to self-defeating male behaviour when it comes to healthcare, saying men posed a 'special problem' for his department and appealing for innovative solutions. He said that during the recent massive 18-month national Health Counselling and Testing (HCT), campaign, only $35 \%$ of people using the service were men. 'Brothers, fathers and children, please wake up!' he urged. 'We're not testing enough of you. Women, please, grab your men and bring them to the testing station, alive and kicking ... drag them there. If they ask questions, refer them to me and I will confront them.'

Motsoaledi said that a consortium of United Nations agencies and development partners, led by UNAIDS, had found that South Africa now has 2.1 million people on antiretroviral drugs (ARVs) with $80 \%$ of eligible HIV-positive women and 65\%

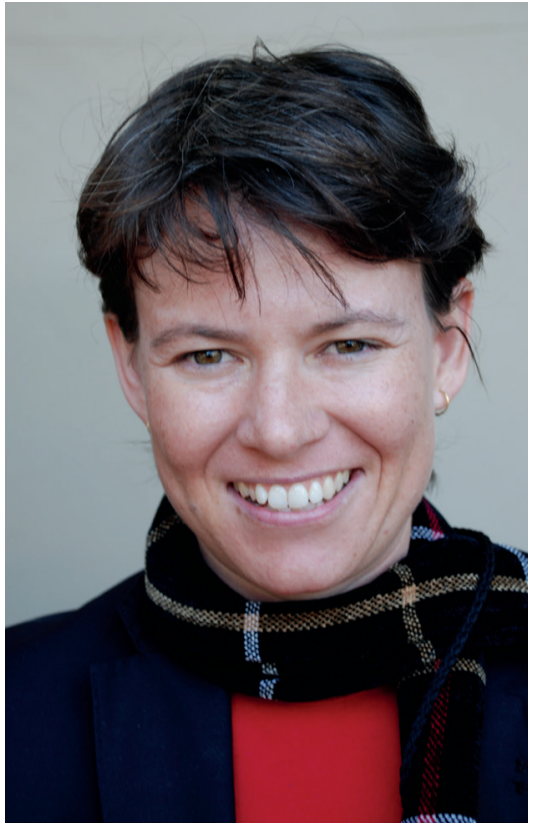

Jacqueline Pienaar, Male Medical Circumcision Lead in South Africa for the US Centre for Disease Control, and a fellow of its NGO, the MAC AIDS Fund.

of eligible men and children (considered as one group) on treatment. These data match South Africa's Human Science's Research Council (HSRC's) 2012 HIV survey. Emphasising the importance of properly targeted behaviour-change interventions, he cited the latest census finding that $49 \%$ of the population are below 24 years old, with joblessness among the youth estimated at
23.6\%. Combined with high HIV rates, this creates a situation some experts are calling a ticking time bomb.

Motsoaledi added that, after factoring in income disparities between genders and the 'sugar daddy syndrome', it was unsurprising that young women were 4 to 8 eight times more susceptible to HIV/AIDS.

Pienaar said that with the proven $60 \%$ HIV-prevention efficacy of male medical circumcision, the government's target is to have circumcised 4,3 million males by June 2016 in order to achieve $80 \%$ immunity for the entire population. The target group is males between 15 and 49 years old, as male HIV prevalence is highest in the $25-40$ age-group. Since 2010, over 1 million men are estimated to have undergone medical circumcision. Pienaar said that rapidly expanding service delivery is an urgent priority, as is creating demand through efforts such as convincing married men and promoting 'the snip' as preventing cervical cancer in their partners. The behaviour change session heard that condom use by those with multiple sexual partners was increasing, with researchers concluding that the safer sex message is 'beginning to get through' to those in highrisk relationships.

\section{Chris Bateman}

chrisb@hmpg.co.za

S Afr Med J 2013;103(9):599-600.

DOI:10.7196/SAMJ.7318 